\title{
Rationalizing Violation: Ordered Accounts of Intentionality in the Breaking of Safety Rules
}

1. J. S. Busby

1. Lancaster University, UK

2. M. Iszatt-White

1. Lancaster University, UK

1. J. S. Busby, Department of Management Science, Lancaster University, Bailrigg Campus, Lancaster, LA1 4YX, UK. Email: j.s.busby@lancaster.ac.uk

\begin{abstract}
Regulative rules are central to the efforts made in organizations to ensure orderliness in the presence of physical danger. The reportedly routine violation of safety rules in organizations therefore brings into question the longstanding association of rules with organizational order, and the literature is sharply divided on whether rule violation represents a dangerous disorder or a reasonable way of getting by. This study is an attempt to carry out a more interpretive analysis, looking at how organizational members construct a sense of order in the presence of rule violation and in particular how they do so by using a concept of intentionality to maintain accountability yet avoid rules becoming taboos. We find that the way people explain intentions attests to several senses of order that otherwise appear to be lost when rules are violated, such as predictability, purposefulness and progressiveness. This indicates that rules do not maintain, symbolize and constitute order simply because they are normative restraints on behaviour - but act as nuclei for discourses that can repair order even when they are violated. The order that is repaired in this way is both a mechanistic and a moral one.
\end{abstract}

\section{An Introduction to the Rule Violation Problem}

The problem we address is how to understand the violation of an organization's formal, regulative rules - the rules it imposes on organizational members to restrain their behaviour in some way. The violations we study are safety rule violations, and the problem we address is not whether violation increases or decreases danger, as has traditionally been examined, but how violation challenges order within an organization. The safety question is what physically happens when rules are violated, whereas the organizational question is what happens socially. To the extent that rules really produce safety, violation produces danger; to the extent that rules really produce order and coordination, violation means disruption and chaos. When studying rules meant to make organizations safer it is natural to examine the relationship between rules and safety. But we suggest it is as important to study the relationship between rules and order, and that disorder can be as harmful to organization as physical danger - and can itself undermine safety when it obscures dangerous discrepancies and drift.

Organizational order has long been associated with rules. Rules have been variously seen as devices that maintain order (Edgerton, 1985), that are symbolic of order (March, Schulz, \& Zhou, 2000, p. 8) and that constitute order of a negotiated kind (Mills \& Murgatroyd, 1991, p. 18). Since rules are 
'more or less stable, more or less exhaustive, and ... can be learned' (Weber, 1978, p. 958), their functionality is inherently orderly, enacting principles of bureaucratic rationality (Mills \& Murgatroyd, 1991), restricting self-interested behaviour (Beck \& Kieser, 2003), and protecting organizational members from the predations of others (Crozier, 1964, p. 189; Merton, 1940). Even though rules are inevitably incomplete, Bittner's (1965) view was that 'Extending to the rule the respect of compliance, while finding in the rule the means for doing whatever needs to be done, is the gambit that characterizes organizational acumen.' Cases where the gambit is not made, where people neglect any 'respect of compliance', therefore look like disruptive acts.

Central to what happens to order when rules are violated is how organizational members reconstruct the relevant 'intentions'. A concept of intentionality has always been needed to avoid rules becoming taboos (Edgerton, 1985). And, regardless of the evidence of how little human choices and decisions actually originate in conscious deliberation (George, 2009), organizational members seem compelled to look for intentions when faced with having to explain rule breaking. As we argue below, the violation of rules - even safety rules - is commonplace and does not lead to any obvious collapse in organization. The issue then becomes what organizational members do with the things they call 'intentions' that can retrieve the order apparently lost in the act of violation. Our research question is: How do organizational members attribute intentions and find order in safety rule violation? And our approach is to use conversational accounts of rule violation as data, analysing the explanations of an organization's members when provoked into describing what they have observed and experienced.

In the remainder of the article, we first show how the literature is divided about the significance of rule violation, especially in the context of safety rules, suggest why intentions matter so much in the explanation of rule violation, and indicate what the literature on intentionality tells us about the function of intentions in organized social life. We then describe a case study in which we analyse organizational members' accounts of rule violations and identify how they recover a sense of order in their explanations. We present a discussion arguing that rule violation provokes discursive processes that move from the space of behaviours to the space of intentions, transform the lack of behavioural compliance into the existence of intentional compliance, and thereby reconstruct order. This order has both mechanistic and moral qualities - aligning individuals with each other, or with the mores of the groups that organize them.

\section{The Rules Literature and the Intentionality Literature}

\section{Our ambivalence about rules and their violation}

The legitimate capacity to decide upon rules and impose them on members is a defining aspect of formal organization (Ahrne \& Brunsson, 2011). As well as imposing restraints, rules have important facilitative functions, for example as media of organizational learning (Kieser, Beck, \& Tainio, 2001), encapsulating past experience as a guide for future action (Douglas, 1986; Scott \& Christensen, $\underline{1995}$ ) and converting tacit knowhow into explicit knowledge (Choo, 2006, p. 163). Rules enhance the substitutability of individuals (Ahrne, 1994, pp. 18-19), retain organizational knowledge beyond individual tenure (Kieser et al., 2001) and transfer experience to new members (Beck \& Kieser, 2003). Rules facilitate coordination (Ahrne, 1994, p. 105) when individual knowledge is

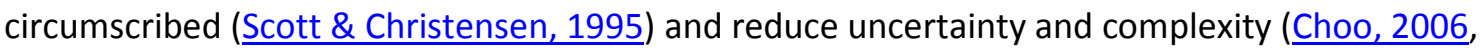
p. 22). The restraints they impose promote personal safety ( $\underline{\text { Hodgson, 2006) }}$ ) and their formalization 
reduces role conflict and ambiguity (Adler \& Borys, 1996). Rules are important resources for people trying to produce understandable and reasonable accounts of their behaviour (Zimmerman, 1970).

Rules are not the same as organizational routines. Routines (Becker, 2004) resemble rules in providing prescriptions for acting in similar situations and, like rules, they facilitate organized behaviour in many respects while impeding it in others (e.g. Cohen \& Bacdayan, 1994). The idea that they have ostensive and performative aspects (Feldman \& Pentland, 2003) that allow continuing adaptation (Pentland, Feldman, Becker, \& Liu, 2012) could apply equally to rules. Yet routines are defined by being repetitive and patterned combinations of actions (Feldman \& Pentland, 2003). Rules, in contrast, are defined primarily by their normative quality. They set up obligations on organizational members to restrain their behaviour in some way, and organizations are granted the right to monitor members and impose sanctions for rule violation (Ahrne \& Brunsson, 2011).

In this light, violation looks antisocial and inimical to organizational order. Tyler and Blader (2005) argue that 'Achieving employee adherence to organizational rules ... is critical for successful coordination and functioning within organizations'. They suggest that violation is commonly not just dysfunctional but deviant and, as Vaughan (1996) shows, such deviance can, in the extreme, become destructively endemic. It is Tyler and Blader's (2005) view that 'organizational researchers should be concerned with identifying optimal strategies for achieving employee rule and policy adherence'. Morrison (2006) similarly suggests that 'Within the organizational literature, the breaking of formal rules is generally viewed as deviant behavior... Rules are assumed to be functional, and thus employees who fail to follow them are assumed to be self-interested or disenfranchised "deviants"...'

Nonetheless, there is a longstanding antithesis to this view that rules are in some simple sense order-producing and violation order-destroying. Part of the critique is that rules harm individual well-being (Adler \& Borys, 1996). They can have a harmful influence on satisfaction, absence and stress (Rousseau, 1978), and are associated with alienation (Bonjean \& Grimes, 1970; Kakabadse, 1986). They also undermine organizational functioning. Dense rule systems produce inflexibility (Ahrne, 1994, p. 105; Beck \& Kieser, 2003; Perrow, 1986, pp. 20-26), encourage goal displacement (e.g. Merton, 1940) and produce a trained incapacity in organizational members (Mascini, 2005; Mills \& Murgatroyd, 1991, p. 128). They can impede as much as facilitate organizational learning and change (Kieser et al., 2001; Beck \& Kieser, 2003), producing blindness and rigidity (Nystrom \& Starbuck, 1984). The way in which rules protect organizational members from interference by subordinates and superiors devalues relationships and robs them of emotional commitment (Crozier, 1964, p. 189). And whether rules really resolve uncertainty is debatable. Their openendedness means that disputes about what is meant by a rule are a recurring feature of organizations (Edgerton, 1985, p. 27). The large numbers of rules found in most organizations also means that considerable deliberation may be needed to work out which rules are applicable in which situations (Levinthal \& Rerup, 2006; Schulman, 1993). Thus rule violation can be reasonable and possibly pro-social, arising from initiative (Morrison, 2006), rather than negligence or malice. And violation may even be necessary as a way of testing rules and the truces around them (Mills \& Murgatroyd, 1991, p. 61).

The key to understanding the significance of rule violation to an organization appears to be the way members construct the intentions that lie behind it. The central quality of rules is their 
impersonality, and it is this impersonality that gives them much of their social legitimacy and avoids arbitrariness and authoritarianism in management (March et al., 2000; Crozier, 1964, p. 54). But this impersonality also produces harshness, rigidity and literalness. Rules that are imposed as completely impersonal devices degenerate into taboos and, as Edgerton (1985, p. 214) argues, we detest taboos. We find it imperative to recognize that people can intend the 'right' thing and still find themselves having to violate a rule; or intend the 'wrong' thing and nonetheless comply with a rule (Reason, Parker, \& Lawton, 1998). By attributing intentions in this way, people make space for reasoning. It gives violators the opportunity to come up with reasons, and represents humans not just as rational agents but as reasoning agents, as members of a conversational species who produce reasons in order to influence others (Pettit, 2002, p. 163).

\section{The construction of intentionality}

As the scholarship on intentionality demonstrates, however, the scientific understanding of intentions is by no means a settled matter. Perhaps the account that most clearly reflects folk notions that people have intentions before they act, and that the intention somehow causes the action, is Bratman's (1987) view of intentions as partial plans: projections of action into the future, extending a person's deliberation beyond the present and coordinating each of their actions with all their other actions, as well as with the actions of others. Intentions, unlike desires, involve commitments, and as such have a degree of inertia and resistance to reconsideration (Bratman, 1987). This idea of intentions as partial plans helps individuals to make some important distinctions for example, between intentions and their by-products. It is common, for instance, to regard rule violations as typically being a 'side effect' (Cohen \& Levesque, 1990) or 'side intention' (Castelfranchi, 1997) of an intention directed at some other outcome. Similarly, people in organizations need the concept of an intention to deal with the way in which someone can comply with a rule not because there is a rule but because it is something they would have done anyway (Searle, 1983, p. 86). Rule makers are in danger of deluding themselves if they see people acting consistently with rules and infer that this was the consequence of making those rules.

This analysis of what we mean by an 'intention' does not mean that intentions have an objective, independent existence, however. Intentions are frequently, if not universally, emergent products of social interaction after the event (Gibbs, 2001). Accounts of intentions as partial plans that cause the action they plan present a third-person, functional explanation that pays insufficient regard to the first-person point of view of justifying oneself (Robins, 1997). And there is considerable psychological evidence of how far actual processes of choice and decision making completely bypass the deliberate, conscious formation of intentions (George, 2009). The psychology literature (e.g. Wegner \& Wheatley, 1999) explains our subjective experience of acting out of intentions as being the correlation of intentions and actions: intentions do not so much cause actions as spring from the same unconscious mechanisms.

Yet, as Malle (2004) demonstrates, it is equally a mistake to ignore the importance of intentions in the way people explain behaviour - because these explanations are themselves social acts. The business of partial plans is how people talk about intentions, whether or not intentions 'really' predate action, and that talk is groundwork for actions like blaming and punishing (Ames et al., 2001). The notion that individuals have intentions allows observers to conclude that they could have done otherwise (Pettit, 2002, p. 172), and thereby hold them accountable for actions like rule violation. 
Correspondingly, such an 'intentional stance' (Dennett, 1987, p. 17; Dennett, 1971) gives those who stand accountable a way of representing themselves as reasonable and predictable, acting out of legitimate 'intentions' rather than arbitrary impulses.

The upshot is that intentions operate less as a psychological mechanism that betrays itself in behaviour, and more as a social construction that betrays itself in conversation. In organizations, intentions are being claimed and attributed by people negotiating with each other, not simply being 'experienced' by isolated individuals. Intentions are contrived before and after events, in dialogue and perhaps monologue, by people engaged in making organization work. Making organization work includes, notably, dealing with rules: for example, ensuring that rules bring about accountability but do not degenerate into taboos. The premise for the study we describe in the remainder of this paper is therefore that understanding rule violation means understanding intentions, and understanding intentions means understanding conversations.

\section{A study in the context of safety rules}

'Danger' is one of the principal categories that give rise to organizational rule-making (Edgerton, 185, p. 230) and, as Gouldner's (1954, p. 187) study demonstrates, safety has long been a highly bureaucratized, rule-ordered domain. Traditionally rules and taboos have been directed at the dangers to groups from errant individuals (Douglas, 1990), but it has become increasingly important for organizations to protect individuals from hazardous working environments, and often from themselves (e.g. Adams, 2003; Simon, 2003). The literature on rules and safety is as divided about the significance of rules as the organizational literature more generally. Important theories of organizational breakdown suggest that violations can be deeply threatening: for example, Vaughan's (1996) account of the Challenger disaster, which points to the central role played by the acceptance and increasing normalization of rule neglect, and Hynes and Prasad's (1997) account of the emergence of 'mock bureaucracies' in which there is wholesale and overt violation of safety rules. But other parts of the literature see rules as contributing to misleading mindsets of invulnerability (Wicks, 2001), as being no more than political gestures in the aftermath of catastrophic failure (Mascini, 2005) and as over-constraining normal work processes (Reason et al., 1998). We should not be surprised that 'it is well known that numerous safety regulations are neither respected nor enforced' (Gherardi, 2006, p. 183).

Our concern is with how the order in organizations can survive such contradictions, and the apparently chronic violation of safety rules. We take 'order' in general to be the regularity that individuals experience meaningfully within an organizational setting. The literature refers to social and organizational order as being constituted by qualities like regularity (Elster, 1989, p. 1; Dermer, 1992), patterning (Sparks, Bottoms, \& Hav, 1996) and coordinated-ness (Elster, 1989, p. 1; Douglas, $\underline{1971}$, p. 2). But the way in which order is negotiated (Strauss, 1978, p. 5), its emergence in retrospective sensemaking (Weick, Sutcliffe, \& Obstfeld, 2005) and its local accomplishment (e.g. Roth, McRobbie, Lucas, \& Boutonne, 1997) all suggest that such regularity is sought by, as much as given to, organizational members who are in the process of seeking meaning. Such regularity can have different manifestations - for example, in the existence and coherence of roles (Barley, 1986), or status hierarchies (e.g. Benjamin \& Podolny, 1999) - and do different kinds of meaningful work. But in all cases it should be evident to us, as observers, for the reason that it is evident to organizational members themselves. The question of how people find order when confronted with 
rule violation therefore centres on how they construct regularities and what makes these regularities relevant to them. In a study of safety rule violation the most obvious way that 'order' becomes relevant is that it has some connection with physical danger, but there is no reason why it should be confined to this.

\section{Research Design and Methods}

\section{Setting}

The setting for the study was the highway construction and maintenance division of a large infrastructure corporation having around 40,000 employees. Its physical operations involved relatively simple technology, with individuals sometimes operating in small maintenance teams at dispersed locations, sometimes in larger groups working on extensive construction sites. The dangers involved in these operations ranged from acute trauma injury to chronic health problems, such as those arising from exposure to noise or vibration. Fatalities for the industry as a whole were notoriously high, and there was considerable institutional pressure on the case study organization to manage safety risks rigorously, coming both from regulatory agencies and from clients. This risk management was in large part based on organizational rules, not least because of the fragmented nature of work across multiple locations. These rules mandated a wide variety of behaviours, ranging from the conduct of risk assessments and the development of 'method statements' through to the wearing of personal protective equipment (PPE) and acting correctly when close to fastmoving traffic. Such rules were meant to ensure the safety of members of the public, and avoid damage to the general environment, as well as protect the health of organizational members. Most rules were restraints on unsafe behaviour in a direct sense: for example, prohibiting the reversing of large vehicles without assistance. All such rules were normative restraints whose violation could bring about legitimate punishment.

\section{Research design}

The objective of the study was to analyse how organizational members constructed accounts of intentionality and order around rule violation. It was therefore concerned with 'the phenomenon of organization as subjective experience' and 'the patterns that make organized action possible' (Smircich, 1983), and equally with how 'a sense of organization is created and maintained' (Mills and Murgatroyd, 1991, p. 8). This naturally led to a concentration on conversation rather than behaviour. The study was entirely qualitative, looking for explanations in the richness of data, not the counting of it (Henwood \& Pidgeon, 1995). It sought to 'describe, decode, translate and otherwise come to terms with the meaning, not the frequency, of certain more or less naturally occurring phenomena in the social world' (Van Maanen, 1979, p. 520). The aim was also to react flexibly to organizational circumstances and themes emerging from the data as they emerged (Cassell \& Symon, 1994). As we explain below, the data came from interviews and conversations in the field, and as our understanding developed so did the prompts and cues we gave to informants. This allowed us to explore in depth, for instance, the kinds of violation and kinds of circumstance to which people gave greatest significance. The study sits broadly within a phenomenological paradigm, recognizing the 'shared subjectivity of researcher and researched' (Eryer, 1991, p. 3). Thus the analysis, as we explain later, finds second-order interpretations of informants' first-order interpretations of rule violation and violators' intentions. It does not examine whether informants were mistaken about someone's 
intentions. The doubtful status of intentions as an objective truth would anyway make such an analysis deeply problematic.

\section{Data collection and analysis}

The setting was first approached by gathering orienting opinion from a set of interviews with managers. This yielded a range of issues around safety and rules that commanded their attention. A programme of fieldwork was then undertaken, which included participation in safety training, observation of a wide range of activities, and informal discussions with site workers. These took place both individually and in small groups, typically when workers were eating their lunch in the site mess rooms. The discussions were unstructured, conducted loosely to an agenda prepared by the researchers that asked interviewees: (1) to explain their roles in the organization; (2) to explain what they thought of how safety was being managed, particularly in the way rules were relied on; (3) to talk about how things went wrong and rules got broken; (4) to discuss the different views they encountered about the best way to manage safety; and (5) to respond to specific issues that had arisen in earlier discussions. The aim was to allow informants to talk, as far as they felt able, in the terms they chose, about their experiences of safety rules, and they were encouraged to take the lead as far as possible. Clearly this looseness is problematic for reliability but is aimed at the kind of validity that requires researchers to adapt their behaviour from one occasion and one informant to another (Miles, 1983). The data taken forward for analysis consisted of: (1) transcripts from 21 recorded interviews with informants ranging across nearly the full range of seniorities in the operating organization, from senior managers through regional local managers to gang foremen and gang members; (2) the field notes made during the course of all the other activities.

The data were analysed by a process of selection and then generalization - that is, an initial searching phase followed by focused coding (Charmaz, 1983; Glaser, 1978). This involved treating transcripts and fieldworker's notes as texts and searching for distinct fragments that quoted, either verbatim or in some abbreviated form, an informant who was describing rule violations. There were 134 such fragments, which varied in length from single sentences to lengthier accounts of up to around 200 words, but were in some way self-contained. An attempt was then made to analyse the way in which these accounts drew on some idea of intentionality. For example, when informants' accounts claimed that someone was 'trying to' comply with a rule, or had 'decided to' violate a rule, we took this as an attribution of intentionality. Examples are given in the next section. We included fragments that denied intentionality as well as those that affirmed it, for example when an informant suggested someone 'had no choice' but to violate a rule. In general, intentionality was inferred by the basic test that the conversation somehow claims the individual being described 'could have done otherwise' (Pettit 2002, p. 172).

The fragments were coded by generalizing on the sense of order being affirmed in the way intentions were being constructed. We had no preconception about what kinds of regularity would be used in informants' accounts, but it had to be evidently meaningful to them. The aim was to see how the informants were constructing regularity, and to then find ways of categorizing their constructions in a way that illuminated what work the regularity was doing. For example, several accounts talked about how someone's intentions were in some way correlated with their disposition, or personality, or 'history'. These were coded at a more general level as 'order as predictability' since they indicated that, although people were violating rules, the attributed 
intentions nonetheless made the violation in some way predictable and to this extent orderly. This coding was not an attempt to partition the data strictly - that is, to force each fragment under only one code. Given the flexibility and ambiguity of natural language, this was neither feasible nor desirable. But the coding was meant to reveal a set of ideal-types that could express what sense of order was being discursively achieved. We should also point out that this procedure did not incorporate an explicit 'first-order' analysis, as recommended by Gioia, Corley and Hamilton (2013), because it seemed reasonable to move straight from informants' accounts to these categories.

\section{An Initial Analysis: The Different Senses of Order}

Five categories emerged from the analysis, expressing the qualitatively distinct ways in which a sense of order was expressed in informants' accounts:

1. Order as predictability - where the intentions underlying the violation of rules, the sometimes misguided attempts to enforce them, and responses to violation, somehow rendered the informants' organizational world predictable.

2. Order as purposefulness - where intentions rendered the world collectively purposeful.

3. Order as progress - where intentions rendered the world as one exhibiting progress over time.

4. Order as affiliation - where intentions rendered the world as one explicable through individuals' affiliations to groups within it.

5. Order as humaneness - where intentions rendered the organizational world as being humane or at least responsive to the principle of humaneness.

In the remainder of this section we explicate the categories, showing how informants constructed intentionality in a way that allowed them to find order of these kinds. In the section that follows we attempt a more general analysis of how rule violation provokes the attributing of intentions and the retrieval of order.

\section{Order as predictability}

Several distinct ways of recovering predictability in the face of rule violation were identifiable in the data. Informants' accounts suggested that certain kinds of people predictably intend to act in a way that knowingly sets rules aside: people who came from organizations with mindsets hostile to rule following, older people who had learned the trade in more permissive organizations, and people whose experience had taught them that rules were unnecessary to staying safe. Some accounts stressed situational features that produced predictability, for example, whether people are being observed:When they know that people aren't actually out there they won't put it on [comply with a rule requiring the wearing of protective clothing], but if they know that someone's out there doing a safety tour they'll do it.

There was also the idea that you can predict behaviour around rules by examining individuals' histories: 'Some people you know you need to be a bit stronger on them because they'll just try it on the next time. So you do take a view, you look at their past history.' The account says that the violator could have done otherwise (they were just 'trying it on'), but that their history predicts their 
intention to comply or violate. Predictability is also rendered by attributing intentions characteristic of people at work generally, for instance the idea of doing work quickly: 'People try to cut corners for speed, they want to get things done as quickly as possible and if they've got to put things in place to do that job they try and bring that down.' Like many accounts, this says that the violator's intention is to work quickly, not to violate the rule - which is merely a by-product.

Some of the predictability was inherently cynical. Behaviour became predictable out of an assumption that people act for bad reasons or are bad by disposition. For instance, there were 'bad apples' who could predictably shape group norms towards rule violation: 'You've got a lot of people working out there and if you have one bad apple... the culture can change, they can sort of think it's acceptable.' This claims that people's intentions towards rules are shaped by perceptions of social acceptability, which predictably can lead to violation if a 'bad apple' has influenced what has become acceptable. In becoming predictable, violation took on the form of recidivism:'You actually work with these people and you can talk to them time and time again about the same things, day in and day out and it's just water off a duck's back. They just do not take it in.'

People can have intentions that become predictably resistant to others' attempts to persuade them to follow rules.

The cynicism was not always directed towards the violator but sometimes towards the rule maker. Another theme, for example, was that you could predict that violations would occur when individuals thought rules existed only to protect managerial reputation: 'Oh they'll just think, "Well, that's just another blimming form" ... so they [managers] can cover their arses...' The quote appears banal, yet it involves attributing to someone an intention towards a rule based on that person's attributing to someone else an intention behind enforcing the rule. The capacities of organizational members to construct meaningful and orderly (if cynical) intentions are thus quite sophisticated - a reflection of the social importance of doing so.

\section{Order as purposefulness}

The second sense of order was purposefulness. In many accounts, a rule violator had an intention that was somehow consistent with, or motivated by, a collective purpose. Most commonly, a rule violator's aim was to maximize efficiency, knowing that a rule was being violated but not having violation as the intention. For example, the following refers to the violation of a rule limiting exposure to harmful vibration:He's on a chainsaw ... everything he does is by choice, so if he chooses to go over the [permissible exposure] time, that's because he's chosen to do that, and he'll justify it in his own way, I suppose. Even though he knows the rules, he'll say, 'well, the job needed doing and I wanted to get it done'

Such explanations are clearly chosen to emphasize the freedom of will and the knowledge that a rule was being violated, yet show that this free will leads to intentions that express an accepted purpose. Another account in a very similar context expresses how intentions were shaped not only by a sense of purpose but also by the imperative to communicate the sense of purpose to others:There was never anybody came and said, 'oh, I need you to do $x$ amount of hours on the saw'. But they all said, 'oh, aren't you doing well, you're catching up.'... To do the work that we were turning out you'd have needed a coach-load of saw operatives, ... obviously I knew the hours that I should be exposing 
myself, but I was driven by wanting to keep my guys motivated and keep them working and keep the programme moving on.

However, there were clear boundary conditions - in particular the idea that a greater good sometimes means setting aside a violator's intentions. The following refers to behaviour on a multilane highway:Over on the other side going northbound there was a car that had broken down. And it was in a vulnerable position, so he decided that... he'd walk across the motorway, and he would go and help him. Site managers' rules strictly state, unless you are putting signs out, you do not walk across the motorway. There was a lorry that [just] missed him... He stepped into lane one of the motorway to try and direct the traffic - that is strictly, strictly no go. He then came back across the carriageway, back across to get into his lorry. In the middle lane, a car coming up in the middle lane had to divert into the outside lane to miss him, which nearly caused an accident because there was a guy coming up here... so he was dismissed, he was absolutely aghast, his intention was... he was absolutely shattered at the fact that we would take him through a disciplinary process.

The way this account conveys the violator's surprise at being punished, despite his good intentions, emphasizes the nature of such cases as boundary conditions, where the normality of exonerating violations accompanied by good intentions is set aside.

Another boundary condition to retrieving order by stressing reasonable purpose was the misattribution of intentions. For example, a rule required drivers to follow a route indicated by their satellite navigational equipment and the following is an explanation of why this rule was violated for good purpose, but with a wrong attribution of intention: 'I'm trying to get to the job... I can't because $A$ is in the way or B is in the way, I've had to go this route... they'll think I've been swanning off somewhere or going shopping or something.' The inherent flexibility with which we can attribute 'intentions' to rule violators means we can appropriately exonerate them, but it also means we can inappropriately blame them.

\section{Order as progress}

'Progress' also appeared in our analysis as a sense of order. In various ways the informants portrayed intentions as being oriented towards, or motivated by, improvement in practice, outcome or circumstances. The main way of affirming this was to see rule violation as being an occasion for learning and re-education: 'So there's always a, there can be an excuse, because sometimes there are legitimate excuses if you like... But we'll make sure there's training available for you... we treat it as a learning exercise...' Portraying violators as having 'excuses' avoids legitimizing violations, but the informant also wants convey that 'we' are enlightened enough to regard violations as vehicles for improvement. The fact that the rules in question were safety rules was also relevant, as informants could construct explanations that represented violation as intentional yet self-evidently contrary to the violator's welfare. This allowed the possibility of progress: 'Education's far better than discipline... You know, I mean it's wilful neglect of his...himself...'

There was also a view that rules themselves were just 'tools' and represented only an intermediate stage for the organization in its progress towards a more ideal state:Rules are not enough to make people safe. Eighty-five percent of their accidents are behavioural-type issues - e.g. a bloke not concentrating because he's had a row with his wife or because a mate distracts him half way through a task... [We are] trying to get people to look at what's going on in their working 
environment - get them to use various tools to think about safety, then throw the tool away when it has done its job and safety is second nature.

This account explains rule violation in terms of distraction. It dilutes its seriousness by asserting that rules can ultimately be discarded when safety is 'second nature'. It is an expression of how progress towards safety is being achieved in an organization, despite rule violation, and it works because rules are portrayed only as scaffolding, not as the ultimate instruments of order.

But there were other discourses that took the opposite view, suggesting rules as ideal end-points rather than scaffolding:The ambiguities, each time [a rule is violated], they get ironed out... So I think in the past we probably haven't spent the time getting the wording exactly right so it's clear and unambiguous... we'll never get a rule for every situation but we try and cover as many as we can.

Progress in this case is not progress beyond rules: it is progress toward increasingly accurate and comprehensive rules, a progress which is facilitated by the ambiguities that violations reveal.

Although they seem to make opposite claims, in both the rules-as-scaffolding and rules-as-end-point discourses the violation of rules can be constructed as being a way of making progress. The violator's intentions are consistent with this because (in the first case) the rule violation is explained by distraction, and (in the second) the violation is explained by ambiguity.

\section{Order as affiliation}

Another sense of order arises when organizational members explain individuals' intentions as originating in their affiliation to groups possessing some system of shared ideas, assumptions or norms. The emic category of 'culture' occurred often in informant accounts, including some quotations already given. Usually this was a way of exonerating the violator without undermining the violated rule. The following refers to a group of workers that had joined the firm from another organization:They're getting used to it, and accepting the reason why we [have so many safety rules]...The problem you get is you have the culture of 'We've never done it this way before, so why are we going to do it now?'

This says that violation had been a shared, collective error: an error in the 'culture'. But it also says that the people in question are reasoning individuals who are coming to accept the reason why there are rules. Similarly:When we took this contract over, they were very, very good at getting the work done, fantastic interface with the public, broke every safety rule in the book ... they can still get the work done but of course there's now the barriers, they perceive them as barriers, and you've got to say, hang on a minute, there's not a barrier here, this is out to protect you so that you do go home to your families.

The root of the violations is again portrayed as being a mistaken belief that exists in the group rather than an individual. In this case it is the specific category error of perceiving a rule as a barrier. The account, like the previous one, also suggests that the violators can be given reasons with which they can intend to comply with the rules rather than violate them.

A boundary condition to exonerating rule violators because of their affiliation arose when violations created danger for people other than the violator. This crossed a categorical boundary that made violations more serious morally, and reduced the importance of inspecting the violator's intentions. A significant variance in the accounts was that some referred to the intentions of bystanders rather 
than the rule violators themselves. Rule violation implicates not just the violator but peers and observers who let them proceed, and we use ideas about intentionality to get them off the hook as well. Some accounts referred to the general idea that people turn a blind eye to rule violation because they want to avoid trouble. One informant referred to the 'culture' of immigrant workers and their understandable intentions to avoid attracting attention to themselves:The guys... tend to be very transient labour... the guys are just trying to make a life for themselves in this country and maybe just want to keep a job. They're hardly going to cause a bit of a fuss about all this. He [the violator] has done five minutes over his breaking time [violating a rule restricting use of vibrating machinery]. So there could be a culture there of just get your head down and do it sort of thing. Some of these guys may not even be legally in the country.

\section{Order as humaneness}

Accounts which attested to individuals acting humanely similarly appeared to affirm a sense of order. For example:We're dealing with Mrs Smith, a pothole outside her house - I sometimes have to say to that woman, 'I might not get there for a week.' Because I have to do a site visit, I have to do a risk assessment, I have to do this ... what I say to her is, 'I'll come round and do it myself, Mrs Smith.' And I have done that, but if anything went wrong my neck's on the line.

This is a self-declared violation committed, according to the informant, for reasons of service to another individual. The claim that he is liable for punishment, if the violation leads to some substantive harm, reinforces the humaneness of his intention and the way in which it is motivated by the service of someone else.

Much of the data expressing humaneness was concerned with the response to violations rather than the violations themselves. For example:It's important to talk to people on safety tours... [We] need the policing of rules, too, but this won't work on its own. Disciplinary action, bollocking them for rule violations, should be the last resort. [We] need to understand why it is happening.

The claim is plainly that rule violators are reasoning individuals and it is important to discover this reasoning - not to punish the act. Similarly, it was seen as being humane to punish only recidivism, not occasional violations:The first port of call is I'll go out and have a ... basically a chat with them, off-the-record type of thing and say 'Right, you've been caught, pack it in.' If they persist in doing it then I'll go down the disciplinary line.

There is no explicit reference to intentionality in this relatively brusque account, but it must assume violations arise from intentional acts as otherwise there would be no point in having a 'chat'.

Impartiality was another criterion that pointed to humaneness in the intentions of people responding to others' violations:I won't just do one, because the guys will think, 'Well, why did you pick on me?' You know, 'John's working just down the road, you must have passed him to get to me, like.'... So it's not personal, and they know it's not personal, and it's also that they know that they can be checked up on at any given time of the day, by anybody who's [got] legitimate cause to pull up on their site.

The barren idea of conditioning people to comply with rules by making violation costly arose very little in the data, echoing Gouldner's (1954, p. 193) findings. For example:Technically you could actually deem it as gross misconduct because of the breach of safety regulations... [But] what we're 
not trying to do is discipline the workforce... What we're trying to do is to say 'Look, wear your hat, it's for your own protection,' not 'If you don't wear your hat you'll be sacked.' It's more 'Wear your hat because it will help you,' not 'It's a rule to comply with.'

Whether, objectively, supervisors 'discipline' the workforce humanely or vengefully, they clearly feel the need to construct a humane-looking account. Similarly, in some reports there was the idea that people had 'wishes' that were to be respected, not denied them by organizational rules, for example:l've always thought that we should be a little more respectful of the blokes' wishes in terms of where they do and where they don't [wear protective equipment]... if there is a risk of head injury they must wear them but where there is minimal, very little risk, no more than you walking down the street, then why should you ask them to wear them if it is not necessary?

The second part of the quote simply says there is no point in enforcing a rule when the restraints it imposes are not needed. But the first part refers to respecting 'wishes', portraying actual or potential violators as people with desires, who form intentions, which can be legitimate even when inconsistent with rules.

\section{A Further Analysis: Rules as Nuclei for Mechanistic and Moral Ordering}

\section{Different kinds of ordering}

The categories that emerged in the organization of our informants' accounts broadly point to two kinds of ordering: one essentially mechanistic, one essentially moral. The mechanistic ordering produces coherence, and helps coordinate one person with another. Order as predictability is most clearly of this kind, as the unpredictability of one person's intentions to another seems almost bound to bring about chaos. Order as purposefulness is similar: finding ways of portraying behaviour as contributing to a common purpose, even when it involves rule violation, helps individuals function jointly. At the same time it also starts to suggest a coherence between individuals and some underlying, shared value. There is some entity other than the relevant individuals that is involved in the work the ordering does. The same is broadly true of order as progress. The category of order as affiliation takes this further. Individuals that accept an affiliation to a group are likely to find their actions more coordinated with those of other group members, but inter-individual consistency now appears secondary to the idea of an individual's actions being governed by the practices and values belonging to a group. This coherence between individual and mores now looks primary, and the coherence between one individual and another derived from it. The category of order as humaneness expresses the moral aspect to order most clearly, where the regularity involves a relationship between individual and mores at a level that transcends narrowly defined groups. It is a construction of an organizational world that is morally ordered, even when organizational rules, or actions that break rules, might seem to militate against it.

We suggest that the order people construct in organizations is therefore best expressed as a double ordering - the coordination of actor with actor (person with person, department with department, and so on), and the alignment of actor with mores. The two, ultimately, will become indistinguishable as qualities that serve person-to-person coordination become valued by a group and therefore part of its mores. And actor-mores alignment helps group members predict and explain the actions of other members so is central to actor-to-actor coordination. But the duality of this definition helps maintain social order as something more than the regularity that enables an 
organization to operate mechanistically. It is probably true to say that most views of social order in the literature have stressed the mechanistic and not the moral. An exception is the work of Sparks et al. (1996) who, writing about social order in the more fraught organizational environment of prisons, regard order as a 'long-standing pattern of social relations (characterized by a minimum level of respect for persons)'. The respect for persons, although parenthetical, looks like a necessary element of their definition. The problem for the Sparks et al. definition is that the moral standard comes from the researcher or observer, rather than the organization under analysis. In our analysis the moral element comes from the people who figure in the informants' accounts. Sometimes the informants were talking about the morality of their own intentions (the humaneness of breaking rules about doing risk assessments, for example), whereas sometimes it was about the morality of others' intentions (the way a group of workers unaccustomed to rules were doing what their 'culture' demanded). Either way, order came from constructing intentions for people that were coherent with whatever mores applied to them. This may, or may not, have been shared with the person putting together the account.

\section{Rules as nuclei for but not producers of order}

In principle it is rules themselves that produce order of both these two kinds - restraining behaviour so that it is orderly. On face value they could not do so if they were violated. Yet informants' accounts demonstrate that, when rules are violated, order does get brought into being, and the violated rules are not incidental to it. Informants' discursive efforts to produce order out of rule violations succeed logically by finding in rule violators' intentions the two kinds of order. And the violated rules express a standard against which actual behaviour can be compared, so, when violated, produce discrepancies that provoke sensemaking (Weick et al., 2005). By definition the rules are normative - there is some kind of legitimate force behind them - and because of this have 'tremendous symbolic significance' (Merton, 1940). When they are violated the violation requires explanation.

The literature described earlier characterizes the link between rules and order in a number of ways: rules as causing order (e.g. Edgerton, 1985); rules as symbolizing order (e.g. March et al., 2000, p. 8); and rules as constituting order (Mills \& Murgatroyd, 1991, p. 18). But if people can find senses of order in rule violation then each of these claims has to be qualified. Rules may or may not cause order, but violation does not (necessarily) cause disorder. Rules may symbolize order, but violation does not stand in the way of finding other symbols when necessary. Rules may sometimes constitute order, but when violation occurs we can see that there are alternative ways of constituting it, at least until certain boundary conditions are encountered.

\section{One conformance replaces another in the shift from behaviours to intentions}

The principle that individuals are creating order out of a violation implies that they are replacing the frustrated conformance to a rule with a successful conformance to some other standard. The categories of the previous section point to what the replacement conformance is. Instead of conforming to rules, people were conforming to some predictable personal disposition (in some cases), the practices of some relevant group, the purpose of some part of the organization, a sentiment towards human beings, and so on. However, the two types of conformance existed in different spaces: rule conformance, which broke down, was in the space of behaviours; the alternative conformance, the search for which was provoked by rule violation, was in the space of 
intentions. Informants made a shift from behaviour to intention when called on to give their accounts. This shift was implied in our original premise that people use intentions to construct their accounts of violations, and in our method of looking for intentions in such accounts. The data that came from the study tell us what kinds of reference in the space of intentions provide potential conformances.

In general we do not explain the occurrence of intentions with causes: we explain them with reasons (Malle, Moses, \& Baldwin, 2001). So in looking for conformances in people's intentions we are examining their reasons, and our standards are kinds of reason rather than kinds of behaviour. This is hardly surprising, given that reasoning and reasonableness are so central in organizations (Pettit, 2002, p. 163; Scott \& Christensen, 1995). Rule violations thus give organizational members an opportunity to examine or reaffirm what they regard as right reasons. But of course it is in the nature of organizations sometimes to develop very unhelpful reasons as standards to conform to. In Vaughan's (1996) account of 'normalised deviance' in the Challenger case, there is a similar analysis of how a non-conformance in one respect (breaking a rule) becomes a conformance in another respect (acting like others, or like managers want you to act). As in our study, the space in which deviance occurs is the concrete, relatively objective space of behaviours and concrete rules. The space in which normalization occurs is the less objective space of endeavouring and social desirability. Unfortunately, in Vaughan's analysis, the replacement conformance - and the kinds of reason that served as standards - turned out to be a lot more dangerous than the conformance it replaced.

This shift in conformance is reflected somewhat similarly in the literature contrasting regulation by law and by morality (e.g. Shavell, 2002). In our study there is often a moral compliance where there is a legal transgression, and the former is used to explain the latter. But again there is a shift that accompanies the move between legal and moral regulation, which Shavell analyses. The rules that get violated prescribe specific behaviours, such as obeying a limit on exposure to vibrating machinery; the morality that gets conformed to prescribes general ideas, such as rendering service to others needing it. While the latter can achieve order in the transgressions of the former, it cannot achieve exactly what the former was meant to achieve at a specific and concrete level.

\section{Conclusions}

Our general conclusion is that the imperative towards order within organizations may lead to rules, and plainly such rules cannot produce order when they are violated. Yet violation provokes a discursive production of order in which rules serve as nuclei - standards whose violation provokes explanation. This involves a shift from dealing with behaviours to dealing with intentions. And this then enables organizational members to replace the non-conformance to the rule with a conformance to something else - a conformance that brings about either a mechanistic coherence or a moral one.

We have suggested that the literature is quite sharply divided on the significance of rule violation for social order. But this is perhaps because it has been mostly concerned with making a third-person judgement rather than exploring the judgements of people having to explain rule violation within the system in which it is taking place. Their explanation is itself a social act, an act that plays at least some part in the construction of order within an organization. There is a strong psychological critique of the idea that intentions have an objective existence, but the social construction, as 
opposed to the psychological fact, of intentions is vital to this process of finding order - particularly when order is construed as a double coordination, both mechanistic and moral.

We suggest that this makes a number of contributions:

It shifts attention from whether rule violation is somehow right or wrong to the way in which its rightness or wrongness is interpreted in an organization - and how this interpretation can find elements of order even when appropriate rules are violated.

It advances the idea that organizational rules provide the sites of structuring, ordering and organization but do not have to be in some simple way the cause or embodiment of it.

It introduces the analysis of intentionality to a literature that has largely taken it as a settled issue and an objective fact and used it only as a definer of categorical boundaries.

It suggests an idea of order within organizations that encompasses both a mechanistic regularity and moral one.

As a qualitative, inductive case study of a specific, if distributed, organization this work has obvious limitations in terms of its generality. Its concern only with rule violation, and neglect of compliance, means that it sheds no particular light on the balance between the two. Nonetheless, the understanding we have developed of how accounts of rules and rule violations are constructed, of how order is found when seemingly the instruments of order are undermined, and of the importance of a concept of intentionality in such constructions, seems to us to be a worthwhile one. It is a way of moving on from the difficulties of working out in some objective sense whether rule violation is good or bad for organization.

Finally, we suggest that the orientation towards intentionality, and its construction, might be pursued by pushing into areas closely related to organizational rules and safety. The violation of safety rules is clearly connected with the work on high reliability organization (HRO) and the remarkable accomplishment of nearly failure-free operation in extreme and complex conditions (Klein, Bigley, \& Roberts, 1995; Roberts \& Rousseau, 1989; Roberts, Madsen, Desai, \& van Stralen, $\underline{2005}$; Rochlin, La Porte, \& Roberts, 1987). HRO work emphasizes the social rather than technological processes that produce this reliability, including flexible patterns of authority (Bigley \& Roberts, 2001; Grabowski \& Roberts, 1997; La Porte \& Consolini, 1991; Roberts, Stout, \& Halpern, 1994), cultures that avoid blame and reward the reporting of error and transgression ((La Porte, 1996; Roberts et al., 2005) and collective mindfulness (Weick, Sutcliffe, \& Obstfeld, 1999). Such processes raise interesting questions about how far reliability appears to depend on individuals successfully anticipating each other's intentions, having the right intentions, having coordinated intentions and so on, when intentions have such a questionable empirical status. Rule violation is similarly connected with literature on the management of error. Violation and error are sometimes seen as conceptual opposites: for example, when violations are defined by being intentional and errors by being unintentional (Van Dyck, Frese, Baer, \& Sonnentag, 2005), or are linked to different cognitive mechanisms (Reason, 1990, p. 197). Extensive field studies of error making (Brodbeck, Zapf, Prümper, \& Ferese, 1993) make no mention at all of rule violation, so also appear to see error making and rule violation as completely disjoint categories. But other parts of the error management literature are more complex, extending to errors that are the subject of procedures or standards 
(Hofmann \& Mark, 2006) and error that involves the cultural tendencies to violate rules (Catino \& Patriotta, 2013). The labelling of some action as an 'error' clearly has much in common with the way intentions are constructed - whether or not an error is described as being intentional - because it involves the impulse to find an explanation when there is some kind of unfavourable, unwanted or inappropriate discrepancy. And calling things errors, or not, is itself a social act in the way that attributing intentions is. Looking at the coherence produced in the way organizational members call acts erroneous, and 'manage' such error, is perhaps therefore as useful a line of exploration as trying to find what explains error as a natural phenomenon.

\section{Acknowledgments}

Many thanks are due to the managers and workers in the firm where this study took place for their considerable assistance and understanding. We are also very grateful to the editor and anonymous reviewers of earlier manuscripts for their extensive insights and advice.

\section{Article Notes}

Funding The work was partly funded by the UK EPSRC through grant EP/C014677/1.

(C) The Author(s) 2015

\section{Author biographies}

Jerry Busby is a senior lecturer in the Department of Management Science at Lancaster University, having held lecturing posts at the University of Bath and Cranfield University. He formerly worked in the engineering industry. His research interests are in risk analysis, the practice and problems of risk management and organizational failure.

Marian Iszatt-White is a lecturer in the Department for Management Learning and Leadership at Lancaster, having formerly worked as group treasurer in a major oil producer and as a training consultant. Her research interests have been in emotional labour and organizational rule violation, and she has taught in leadership and organizational behaviour generally.

\section{References}

Ericson R. V., Doyle A. Adams J. (2003). Risk and morality: Three framing devices. In Ericson R. V., Doyle A. (Eds.), Risk and morality (pp. 87-104). Toronto: University of Toronto Press.

Adler P. S., Borys B. (1996). Two types of bureaucracy: Enabling and coercive. Administrative Science Quarterly, 41, 61-89.

Ahrne G. (1994). Social organizations. London: SAGE Publications.

Ahrne G., Brunsson N. (2011). Organization outside organizations: The significance of partial organization. Organization, 18, 83-104.

Malle B. F., Moses L. J., Baldwin D. A. Ames D. R., Knowles E. D., Morris M. W., Kalish C. W., Rosati A. D., Gopnik A. (2001). The social folk theorist: Insights from social and cultural psychology on the 
contents and contexts of folk theorizing. In Malle B. F., Moses L. J., Baldwin D. A. (Eds.), Intentions and intentionality: Foundations of social cognition (pp. 307-329). Cambridge, MA: MIT Press.

Barley S.R. (1986). Technology as an occasion for structuring: Evidence from observations of CT scanners and the social order of radiology departments. Administrative Science Quarterly, 31, 78108.

Beck N., Kieser A. (2003). The complexity of rule systems, experience and organizational learning. Organization Studies, 24, 793-814.

Becker M. C. (2004). Organizational routines: A review of the literature. Industrial and Corporate Change, 13, 643-677.

Benjamin B. A., Podolny J. M.

(1999). Status, quality, and social order in the California wine industry. Administrative Science Quarterly, 44, 563-589.

Abstract/FREE Full Text

1. $\Perp$

1. Bigley G. A.,

2. Roberts K.H.

(2001). The incident command system: High reliability organizing for complex and volatile task environments. Academy of Management Journal, 44, 1281-1300.

Abstract/FREE Full Text

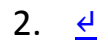

1. Bittner E.

(1965). The concept of organization. Social Research, 32, 239-255.

Find it in OneSearchWeb of ScienceGoogle Scholar

3. $\Perp$

1. Bonjean C. M.,

2. Grimes M. D.

(1970). Bureaucracy and alienation: A dimensional approach. Social Forces, 48, 365-373.

Abstract/FREE Full Text

4. $\underline{\Perp}$

1. Bratman M. E. 
(1987). Intention, plans, and practical reason. Cambridge, MA: Harvard University Press.

$\underline{\text { Google Scholar }}$

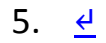

1. Brodbeck F. C.,

2. Zapf D.,

3. Prümper J.,

4. Ferese M.

(1993). Error handling in office work with computers: A field study. Journal of Occupational and Organizational Psychology, 66, 303-317.

Find it in OneSearchCrossRefGoogle Scholar

6. $\Perp$

1. Cassell C.,

2. Symon $\mathrm{G}$.

3. Cassell C.,

4. Symon G.

(1994). Qualitative research in work contexts. In Cassell C., Symon G. (Eds.), Qualitative methods in organizational research: A practical guide (pp. 1-13). London: SAGE Publications.

\section{Google Scholar}

7. $\Perp$

1. Holmström-Hintikka G.,

2. Tuomela R.

3. Castelfranchi C.

(1997). Principles of individual social action. In Holmström-Hintikka G., Tuomela R. (Eds.), Contemporary action theory. Volume 2: social action (pp.163-192). Dordrecht, Netherlands: Kluwer. $\underline{\text { Google Scholar }}$

8. $\stackrel{\leftrightarrow}{-}$

1. Catino M.,

2. Patriotta G. 
(2013). Learning from errors: Cognition, emotions and safety culture in the Italian Air Force. Organization Studies, 34, 437-467.

$\underline{\text { Abstract/FREE Full Text }}$

9. $\Perp$

1. Van Maanen J.

2. Charmaz K.

(1983). The grounded theory method: An explication and interpretation. In Van Maanen J. (Ed.), Qualitative methodology (pp.109-126). Beverly Hills, CA: SAGE Publications.

Google Scholar

10. $\leftrightarrows$

1. Choo C. W.

(2006). The knowing organization. New York: Oxford University Press.

$\underline{\text { Google Scholar }}$

11.

1. Cohen P. R.,

2. Levesque H. J.

(1990). Intention is choice with commitment. Artificial Intelligence, 42, 213-261.

Find it in OneSearchCrossRefWeb of ScienceGoogle Scholar

12. $\Perp$

1. Cohen M. D.,

2. Bacdayan P.

(1994). Organizational routines are stored as procedural memory: Evidence from a laboratory study. Organization Science, 5, 554-568.

Find it in OneSearchCrossRefWeb of ScienceGoogle Scholar

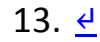

1. Crozier M.

(1964). The bureaucatic phenomenon. London: Tavistock Press.

Google Scholar

14. \pm 
1. Dennett D. C.

(1971). Intentional systems. Journal of Philosophy, 68, 87-106.

Find it in OneSearchCrossRefGoogle Scholar

15. $\Perp$

1. Dennett D. C.

(1987). The intentional stance. Cambridge, MA: MIT Press.

$\underline{\text { Google Scholar }}$

16. $\Perp$

1. Emmanuel C.,

2. Otley D.,

3. Merchant K.

4. Dermer J.

(1992). Control and organizational order. In Emmanuel C., Otley D., Merchant K. (Eds.), Readings in accounting for management control (pp. 132-148). New York: Springer.

$\underline{\text { Google Scholar }}$

17. $\Perp$

1. Douglas J. D.

(1971). American social order: Social rules in a pluralistic society. New York: Free Press.

$\underline{\text { Google Scholar }}$

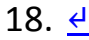

1. Douglas M.

(1986). How institutions think. Syracuse, NY: Syracuse University Press.

Google Scholar

19. $\Perp$

1. Douglas M.

(1990). Risk as a forensic resource. Daedalus, 119, 1-16.

$\underline{\text { Find it in OneSearchGoogle Scholar }}$

20. $\Perp$ 
1. Edgerton R. B.

(1985). Rules, exceptions, and social order. Berkeley: University of California Press.

$\underline{\text { Google Scholar }}$

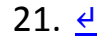

1. Elster J.

(1989). The cement of society: A study of social order. Cambridge, UK: Cambridge University Press.

$\underline{\text { Google Scholar }}$

22. $\Perp$

1. Feldman M. S.,

2. Pentland B. T.

(2003). Reconceptualizing organizational routines as a source of flexibility and change.

Administrative Science Quarterly, 48, 94-118.

Abstract/FREE Full Text

23. $\leftrightarrows$

1. Fryer D.

(1991). Qualitative methods in occupational psychology: Reflections upon why they are so useful but so little used. The Occupational Psychologist, 14, 3-6.

Find it in OneSearchGoogle Scholar

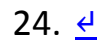

1. George J.M.

(2009). The illusion of will in organizational behavior research: Nonconscious processes and job design. Journal of Management, 35, 1318-1339.

Abstract/FREE Full Text

25. $\leftrightarrow$

1. Gherardi S.

(2006). Organizational knowledge: The texture of workplace learning. Malden, MA: Blackwell.

\section{$\underline{\text { Google Scholar }}$}

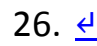

1. Malle B. F., 
2. Moses L. J.,

3. Baldwin D. A.

4. Gibbs R. W.

(2001). Intentions as emergent products of social interactions. In Malle B. F., Moses L. J., Baldwin D. A. (Eds.), Intentions and intentionality: Foundations of social cognition (pp. 105-122). Cambridge, MA: MIT Press.

$\underline{\text { Google Scholar }}$

27.

1. Gioia D. A.,

2. Corley K. G.,

3. Hamilton A. L.

(2013). Seeking qualitative rigor in inductive research. Organizational Research Methods, 16, $15-31$.

Abstract/FREE Full Text

28.

1. Glaser B.

(1978). Theoretical sensitivity. Mill Valley, CA: Sociology Press.

Google Scholar

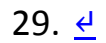

1. Gouldner A. W.

(1954). Patterns of industrial bureaucracy. Glencoe, IL: Free Press.

Google Scholar

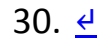

1. Grabowski M.,

2. Roberts K.

(1997). Risk mitigation in large-scale systems: Lessons from high reliability organizations. California Management Review, 39, 152-161.

\section{$\underline{\text { FREE Full Text }}$}

31. 느

1. Henwood K., 
2. Pidgeon $\mathrm{N}$.

(1995). Grounded theory and psychological research. The Psychologist: Bulletin of the British Psychological Society, 8, 115-118.

Find it in OneSearchGoogle Scholar

32. $\Perp$

1. Hodgson G. M.

(2006). What are institutions? Journal of Economic Issues, 40, 1-25.

Find it in OneSearchWeb of ScienceGoogle Scholar

33. $\Perp$

1. Hofmann D. A.,

2. Mark B.

(2006). An investigation of the relationship between safety climate and medication errors as well as other nurse and patient outcomes. Personnel Psychology, 59, 847-869.

Find it in OneSearchCrossRefGoogle Scholar

34. $\underline{4}$

1. Hynes T.,

2. Prasad P.

(1997). Patterns of 'mock bureaucracy' in mining disasters: An analysis of the Westray coal mine explosion. Journal of Management Studies, 34, 601-623.

Find it in OneSearchCrossRefGoogle Scholar

35. $\Perp$

1. Kakabadse A.

(1986). Organizational alienation and job climate. Small Group Research, 17, 458-471.

Abstract

36. $\Perp$

1. Dierkes M.,

2. Berthoin A. A.,

3. Child J.,

4. Nonaka I. 

5. Kieser A.,
6. Beck N.,
7. Tainio R.

(2001). Rules and organizational learning: The behavioral theory approach. In Dierkes M., Berthoin A. A., Child J., Nonaka I. (Eds.), Handbook of organizational learning and knowledge (pp. 598-623). Oxford, UK: Oxford University Press.

Google Scholar

37. $\Perp$

1. Klein R. L.,

2. Bigley G. A.,

3. Roberts K. H.

(1995). Organizational culture in high reliability organizations: An extension. Human Relations, 48, 771-793.

$\underline{\text { Abstract }}$

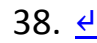

1. La Porte T. R.

(1996). High reliability organizations: Unlikely, demanding and at risk. Journal of Contingencies and Crisis Management, 4, 60-71.

Find it in OneSearchCrossRefGoogle Scholar

39. $\Perp$

1. La Porte T. R,

2. Consolini P. M.

(1991). Working in practice but not in theory: Theoretical challenges of 'high reliability organizations'. Journal of Public Administration Research and Theory, 1, 19-47.

\section{FREE Full Text}



1. Levinthal D.,

2. Rerup C.

(2006). Crossing an apparent chasm: Bridging mindful and less-mindful perspectives on organizational learning. Organization Science, 17, 502-513. 
Find it in OneSearchCrossRefWeb of ScienceGoogle Scholar

41. $\leftrightarrows$

1. Malle B. F.

(2004). How the mind explains behavior. Cambridge, MA: MIT Press.

$\underline{\text { Google Scholar }}$

42. \pm

1. Malle B. F.,

2. Moses L. J.,

3. Baldwin D. A.

4. Malle B. F.,

5. Moses L. J.,

6. Baldwin D. A.

(2001). Introduction: The significance of intentionality. In Malle B. F., Moses L. J., Baldwin D. A. (Eds.), Intentions and intentionality: Foundations of social cognition (pp. 1-24). Cambridge, MA: MIT Press.

Google Scholar

43. $\Perp$

1. March J. G.,

2. Schulz M.,

3. Zhou X.

(2000). The dynamics of rules. Stanford, CA: Stanford University Press.

$\underline{\text { Google Scholar }}$

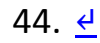

1. Mascini P.

(2005). The blameworthiness of health and safety rule violations. Law and Policy, 27, 472-490.

Find it in OneSearchCrossRefGoogle Scholar

45. $\leftrightarrows$

1. Merton R. K.

(1940). Bureaucratic structure and personality. Social Forces, 18, 560-568. 


\section{$\underline{\text { FREE Full Text }}$}

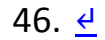

1. Van Maanen J.

2. Miles M. B.

(1983). Qualitative data as an attractive nuisance: The problem of analysis. In Van Maanen J. (Ed.), Qualitative methodology (pp.117-134). Beverly Hills, CA: SAGE Publications.

Google Scholar

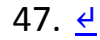

1. Mills A. J.,

2. Murgatroyd S. J.

(1991). Organizational rules: A framework for understanding organizational action. Milton Keynes, UK: Open University Press.

Google Scholar

48.

1. Morrison E. W.

(2006). Doing the job well: An investigation of pro-social rule breaking. Journal of Management, 32, $5-28$.

\section{Abstract/FREE Full Text}

49. $\leftrightarrows$

1. Nystrom P. C.,

2. Starbuck W. H.

(1984). To avoid organizational crises, unlearn. Organizational Dynamics, 13, 53-65.

Find it in OneSearchCrossRefWeb of ScienceGoogle Scholar

50. $\leftrightarrow$

1. Pentland B. T.,

2. Feldman M. S.,

3. Becker M. C.,

4. Liu P. 
(2012). Dynamics of organizational routines: A generative model. Journal of Management Studies, 49, 1484-1508.

Find it in OneSearchCrossRefGoogle Scholar

51. $\Perp$

1. Perrow C.

(1986). Complex organizations: A critical essay (3rd edition). New York: Random House.

Google Scholar

52. $\underline{4}$

1. Pettit P.

(2002). Rules, reasons, and norms. Oxford, UK: Oxford University Press.

Google Scholar

53. $\leftrightarrows$

1. Reason J.

(1990). Human error. Cambridge, UK: Cambridge University Press.

$\underline{\text { Google Scholar }}$

54. $\leftrightarrow$

1. Reason J.,

2. Parker D.,

3. Lawton R.

(1998). Organizational controls and safety: The varieties of rule-related behavior. Journal of Occupational and Organisational Psychology, 71, 289-304.

Find it in OneSearchCrossRefGoogle Scholar

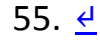

1. Roberts K. H.,

2. Rousseau D. M.

(1989). Research in nearly failure-free, high-reliability organizations: Having the bubble. IEEE Transactions on Engineering Management, 36, 132-139.

Find it in OneSearchCrossRefGoogle Scholar

56. $\Perp$ 
1. Roberts K. H.,

2. Madsen P.,

3. Desai V.,

4. Van Stralen D.

(2005). A case of the birth and death of a high reliability healthcare organization. Quality and Safety in Health Care, 14, 216-220.

\section{Abstract/FREE Full Text}

57. $\Perp$

1. Roberts K. H.,

2. Stout S. K.,

3. Halpern J. J.

(1994). Decision dynamics in two high reliability organizations. Management Science, 40, 614-624.

Find it in OneSearchCrossRefGoogle Scholar

58. $\Perp$

1. Holmström-Hintikka G.,

2. Tuomela R.

3. Robins M. H.

(1997). The place of vows in the theory of bounded rationality. In Holmström-Hintikka G., Tuomela R. (Eds.), Contemporary action theory. Volume 2: social action (pp. 193-210). Dordrecht, Netherlands: Kluwer.

$\underline{\text { Google Scholar }}$

59. $\underline{4}$

1. Rochlin G. I.,

2. La Porte T. R.,

3. Roberts K. H.

(1987). The self-designing high reliability organization: Aircraft carrier operations at sea. Naval War College Review, 40, 76-90.

Find it in OneSearchGoogle Scholar

60. $\Perp$ 
1. Roth W.-M.,

2. McRobbie C. J.,

3. Lucas K. B.,

4. Boutonne S.

(1997). The local production of order in traditional science laboratories: A phenomenological analysis. Learning and Instruction, 7, 107-136.

Find it in OneSearchCrossRefGoogle Scholar

61. $\Perp$

1. Rousseau D. M.

(1978). Characteristics of departments, positions, and individuals: Context for attitudes and behavior. Administrative Science Quarterly, 23, 521-540.

Find it in OneSearchCrossRefWeb of ScienceGoogle Scholar

62. $\Perp$

1. Schulman P. R.

(1993). The negotiated order of organizational reliability. Administration and Society, 25, 353-372.

$\underline{\text { Abstract }}$

63. $\leftrightarrows$

1. Scott W. R.,

2. Christensen S.

3. Scott W. R.,

4. Christensen S.

(1995). Conclusion. In Scott W. R., Christensen S. (Eds.), The institutional construction of organizations (pp. 302-313). Thousand Oaks, CA: SAGE Publications.

$\underline{\text { Google Scholar }}$

64. $\Perp$

1. Searle J. R.

(1983). Intentionality. Cambridge, UK: Cambridge University Press.

Google Scholar

65. 4 
1. Shavell S.

(2002). Law versus morality as regulators of conduct. American Law and Economics Review, 4, 227257.

$\underline{\text { Abstract }}$

66. $\Perp$

1. Ericson R. V.,

2. Doyle A.

3. Simon J.

(2003). Risking rescue: High altitude rescue as moral risk and moral opportunity. In Ericson R. V., Doyle A. (Eds.), Risk and morality (pp. 375-406). Toronto: University of Toronto Press.

\section{$\underline{\text { Google Scholar }}$}

67.

1. Smircich L.

(1983). Concepts of culture and organizational analysis. Administrative Science Quarterly, 28, 339358.

Find it in OneSearchCrossRefWeb of ScienceGoogle Scholar

68. $\Perp$

1. Sparks R.,

2. Bottoms A. E.,

3. Hay W.

(1996). Prisons and the problem of order. Oxford, UK: Clarendon Press.

$\underline{\text { Google Scholar }}$

69. $\Perp$

1. Strauss A.

(1978). Negotiations. San Francisco: Jossey-Bass.

\section{Google Scholar}

70. $\leftrightarrows$

1. Tyler T. R.,

2. Blader S. L. 
(2005). Can business effectively regulate employee conduct? The antecedents of rule following in work settings. Academy of Management Journal, 48, 1143-1158.

Abstract/FREE Full Text

71. $\Perp$

1. Van Dyck C.,

2. Frese M.,

3. Baer M.,

4. Sonnentag S.

(2005). Organizational error management culture and its impact on performance: A two-study replication. Journal of Applied Psychology, 90, 1228-1240.

Find it in OneSearchCrossRefMedlineOrder article via InfotrieveWeb of ScienceGoogle Scholar

72. $\stackrel{4}{ }$

1. Van Maanen J.

(1979). Reclaiming qualitative methods for organizational research: A preface. Administrative Science Quarterly, 24, 520-526.

Find it in OneSearchCrossRefWeb of ScienceGoogle Scholar

73. $\Perp$

1. Vaughan D.

(1996). The Challenger launch decision. Chicago: University of Chicago Press.

Google Scholar

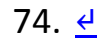

1. Weber M.

(1978). Economy and society: An outline of interpretive sociology. Berkeley: University of California Press.

$\underline{\text { Google Scholar }}$

75. $\Perp$

1. Wegner D. M.,

2. Wheatley T. 
(1999). Apparent mental causation: Sources of the experience of will. American Psychologist, 54, 480-492.

Find it in OneSearchCrossRefMedlineOrder article via InfotrieveWeb of ScienceGoogle Scholar

76. $\Perp$

1. Weick K. E.,

2. Sutcliffe K. M.,

3. Obstfeld D.

(1999). Organizing for high reliability: Processes of collective mindfulness. Research in Organizational Behavior, 21, 81-123.

Find it in OneSearchWeb of ScienceGoogle Scholar

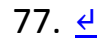

1. Weick K. E.,

2. Sutcliffe K. M.,

3. Obstfeld D.

(2005). Organizing and the process of sensemaking. Organization Science, 16, 409-421.

Find it in OneSearchCrossRefWeb of ScienceGoogle Scholar

78. $\leftrightarrows$

1. Wicks D.

(2001). Institutional mindsets of invulnerability: Differentiated institutional fields and the antecedents of organizational crisis. Organization Studies, 22, 659-692.

\section{Abstract/FREE Full Text}

79. \pm

1. Douglas J. D.

2. Zimmerman D. H.

(1970). The practicalities of rule use. In Douglas J. D. (Ed.), Understanding everyday life: Towards the reconstruction of sociological knowledge (pp. 221-238). Chicago: Aldine.

$\underline{\text { Google Scholar }}$ 